\title{
GABA-Mediated Inhibition of Locus Coeruleus from the Dorsomedial Rostral Medulla
}

\author{
Matthew Ennis and Gary Aston-Jones ${ }^{\mathrm{a}}$ \\ Department of Biology and Center for Neural Science, New York University, New York, New York 10003
}

\begin{abstract}
Recent anatomic studies in our laboratory (Aston-Jones et al., 1986) identified the nucleus prepositus hypoglossi (PrH) in the dorsomedial medulla as a major afferent of the locus coeruleus (LC). In the present studies, the influence of projections from PrH to LC was assessed in anesthetized rats. Focal electrical stimulation of PrH inhibited the spontaneous discharge of 42 of 47 LC neurons; the latency to onset of such inhibition was $19.8 \pm 2.5 \mathrm{msec}$ and its duration was $172.4 \pm 10.4 \mathrm{msec}$. PrH-evoked inhibition of LC neurons was unaffected by administration of the opiate receptor antagonist naloxone or the $\alpha_{2}$-receptor antagonist idazoxan but was substantially reduced by systemic picrotoxin, an antagonist of GABA. The GABA ${ }_{A}$ receptor antagonist bicuculline methiodide blocked the inhibition from PrH, whether applied by local microinfusion or iontophoresis into the LC. These results lead us to propose that PrH provides a direct inhibitory synaptic input to LC, for which GABA is the likely transmitter.
\end{abstract}

Recent anatomic studies (Aston-Jones et al., 1986; Pieribone et al., 1988) demonstrate that the nucleus locus coeruleus (LC) receives a restricted number of afferent inputs, with the bulk of LC innervation arising from 2 medullary nuclei: nucleus prepositus hypoglossi $(\mathrm{PrH})$, previously reported to innervate LC (Cedarbaum and Aghajanian, 1978b), in the dorsomedial medulla (Altman and Bayer, 1980) and the nucleus paragigantocellularis in the ventrolateral medulla. The strong input to the LC from these 2 nuclei indicates that they may be the predominant elements controlling the divergent efferent network of this noradrenergic system. In agreement with these anatomical results, recent electrophysiological experiments reveal that nucleus paragigantocellularis exerts a robust, predominantly excitatory influence on LC (Ennis and Aston-Jones, 1986a, 1988).

The physiologic influence of the other major afferent, $\mathrm{PrH}$, on LC has not been characterized. Immunocy tochemical studies reveal that neurons in the $\mathrm{PrH}$ area stain for markers of several neurotransmitters reported to innervate LC, including $\mathrm{ACh}$

Received Oct. 31, 1988; revised Feb. 1, 1989; accepted Feb. 2, 1989.

This work was supported by PHS Grants MH09381, NS24698, ONR/Air Force Office of Scicntific Research Contract N00014-86-K-0493. We thank Alan North for helpful comments on the manuscript, Klaus Leibold, Floyd Bloom, Mike Palmer, and Barry Hoffer for computer software, and Guy Chouvet and Hideo Akoaka for advice on iontophoretic pipettes.

Correspondence should be addressed to Matthew Ennis, Department of Physiology and Biophysics, ML 576, University of Cincinnati College of Medicine, 231 Bethesda Avenue, Cincinnati, $\mathrm{OH} 45267$.

a Present address: Division of Behavioral Neurobiology, Department of Mental Health Science, Hahnemann University, Broad and Vine Streets, Philadelphia PA 19102.

Copyright $(1989$ Society for Neuroscience $0270-6474 / 89 / 082973-09 \$ 02.00 / 0$
(Palkovits and Jacobowitz, 1974), epinephrine (Hökfelt et al., 1974, 1984; Howe et al., 1980), enkephalins (Khachaturian et al., 1983), and GABA (Mugnaini and Oertel, 1985; V. Pieribone, G. Aston-Jones, and M. Shipley, unpublished observations). It was the purpose of these experiments to ascertain the physiological influence of $\mathrm{PrH}$ on LC and to identify the transmitter(s) mediating synaptic transmission in this pathway.

\section{Materials and Methods}

Stimulation electrode implantation. Male Sprague-Dawley rats (275$375 \mathrm{gm}$ ) were anesthetized with $400 \mathrm{mg} / \mathrm{kg}$ chloral hydrate intraperitoneally. Anesthesia was maintained throughout experiments with additional injections of chloral hydrate as needed. Core temperature was maintained at $36-38^{\circ} \mathrm{C}$ with a feedback-controlled heating pad. Rats were intubated with a tracheal cannula and placed in a stereotaxic instrument with the snout lowered to place the skull $20^{\circ}$ from the horizontal plane. The skin and neck muscles overlying the medulla were excised, and the occipital plate was removed. The dura covering the medulla and caudal cerebellum were removed to expose the caudal apex of the IVth ventricle. A stimulation electrode, consisting of a pair of twisted 125- $\mu$ m-diameter wires, was implanted in $\operatorname{PrH}(2.1-2.5 \mathrm{~mm}$ rostral to obex, $0.1-0.5 \mathrm{~mm}$ lateral to midline, $0.1-0.5 \mathrm{~mm}$ below the dorsal medullary surface). Extracellular recordings were used to localize the $\mathrm{PrH}$ before stimulation electrode implantation as follows. A recording micropipette was centered at the coordinates for PrH (above) and lowered through the cerebellum. The depth of the dorsal medullary surface was noted, and the stimulation electrode was implanted $0.1-0.5$ $\mathrm{mm}$ below the dorsal medullary surface. In addition, 2 electrodes ( 26 gauge needles) were placed subcutaneously in the medial footpad contralateral to recording sites for bipolar stimulation of the sciatic nerve (Aston-Jones et al., 1982; Ennis and Aston-Jones, 1986b). Stimulation electrodes were connected to a Grass S88 stimulator and a constantcurrent stimulus isolation unit (Grass PSIU6). Logic pulses synchronized with brain or footpad stimuli were led to a computer for on-line peristimulus time histogram generation.

$L C$ recordings. In the above animals, a hole was drilled in the skull at the coordinates for $\mathrm{LC}(4.7 \mathrm{~mm}$ posterior to lambda, $1.2 \mathrm{~mm}$ lateral to midline), and the underlying dura was reflected. A glass micropipette (2-4 $\mu \mathrm{m}$ tip diameter, 10-20 M 2 impedance) filled with $2 \%$ pontamine sky blue in $0.5 \mathrm{~m}$ sodium acetate was stereotaxically positioned in the LC area with a hydraulic microdrive. Extracellular recordings from individual neurons were amplified and displayed as filtered $(500 \mathrm{~Hz}-$ $10 \mathrm{kHz}$ bandpass) and unfiltered electrode signals. Action potentials were isolated from background activity with a waveform discriminator that generated logic pulses for signals that crossed a lower voltage gate, peaked below an upper voltage gate, and passed through a time window at a preset voltage and delay. Logic pulses were led to a computer and a chart recorder for on-line data collection. Impulse activity was also monitored with a loudspeaker.

LC neurons were tentatively identified at the time of recording on the basis of characteristic impulse waveforms and spontaneous and evoked discharge patterns as previously reported (Cedarbaum and Aghajanian, 1978a; Ennis and Aston-Jones, 1988). After stable recordings were obtained from a single LC cell, responses to electrical stimulation of PrH were examined and a peristimulus time histogram was generated on-line by computer. Stimuli were monophasic square wave pulses, $0.5 \mathrm{msec}$ in duration, and $0.1-1.0 \mathrm{~mA}$ in amplitude. Peristimulus 


\section{A}
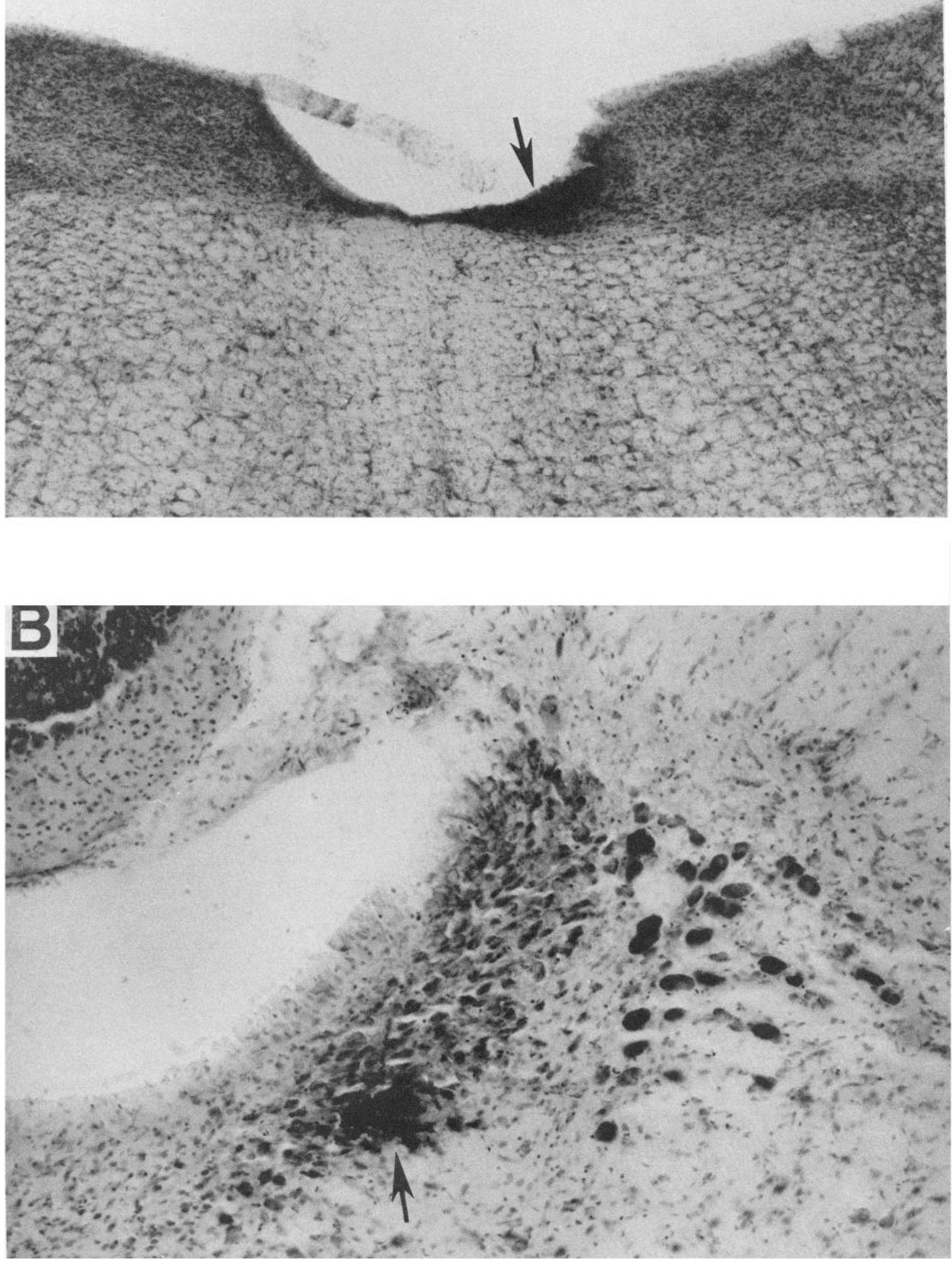


\section{PrH Stim.}

FS
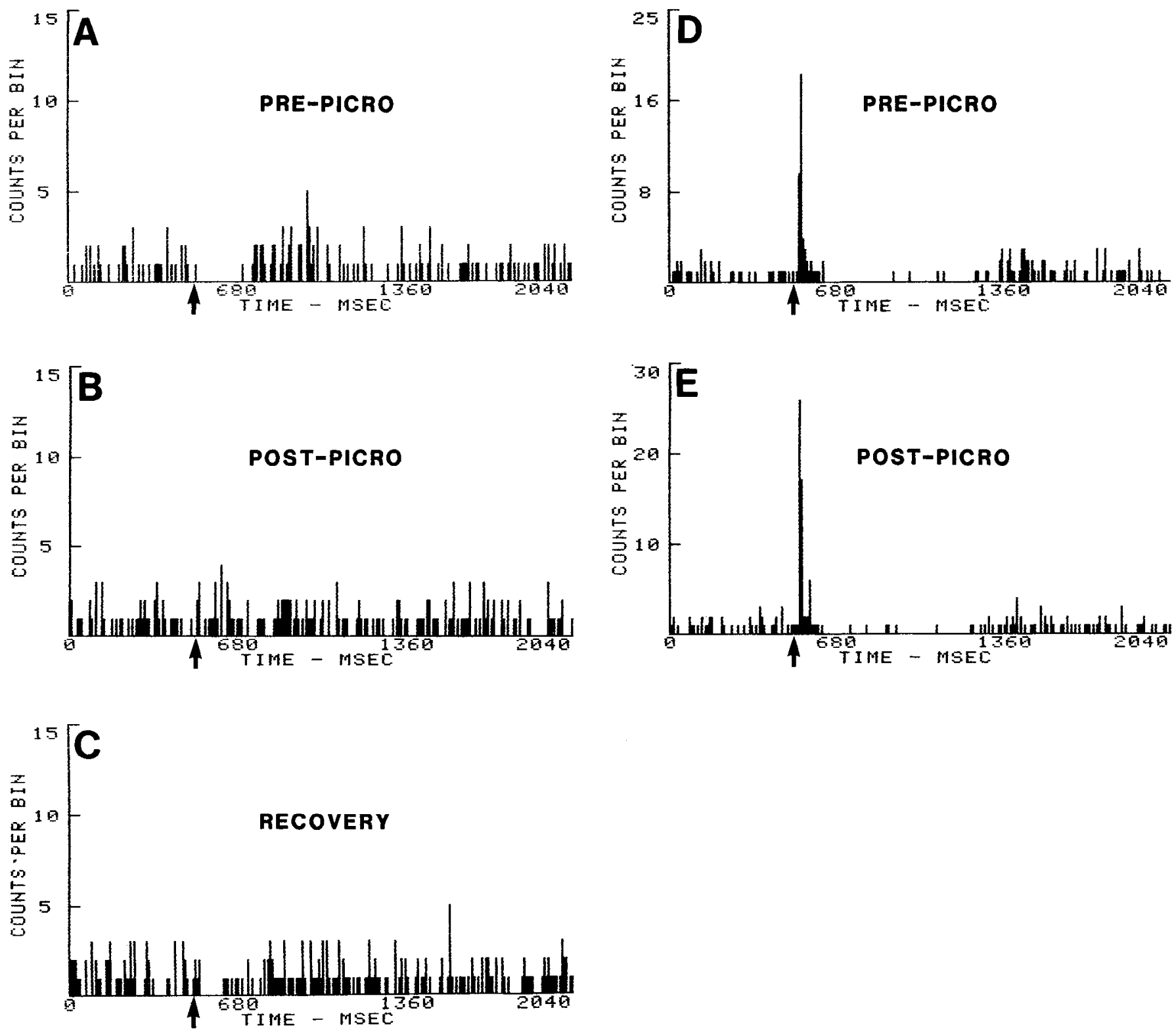

Figure 2. Picrotoxin (PICRO) blocks PrH-evoked inhibition of LC. A, Peristimulus time histogram generated during $0.5 \mathrm{~Hz}$ electrical stimulation (at arrow) of $\mathrm{PrH}$ revealing short-latency inhibition of a typical LC neuron. $B$, PrH-evoked inhibition shown in $A$, predrug, is completely blocked in the same neuron $9 \mathrm{~min}$ after $6.0 \mathrm{mg} / \mathrm{kg}$ (iv) PICRO, as shown in $B$, postdrug. $C$, PrH-evoked inhibition of this cell recovers $33 \mathrm{~min}$ after PICRO administration. Stimulation intensity in $A-C, 600 \mu \mathrm{A}$. D. Peristimulus time histogram showing activation of a LC neuron (same cell as shown in $A-C)$ following footpad stimulation $(F S)$. $E$, FS-evoked excitation of this cell is not altered after the same dose of PICRO as in $B$, as shown in $E$, postdrug. Note also that postactivation inhibition following FS-evoked excitation is not blocked by PICRO. Stimulation amplitude in $D$ and $E$, $20 \mathrm{~V}$. Each histogram was accumulated for 50 consecutive stimulus trials.

time histograms, typically generated at 1.5 times the threshold for apparent inhibition, or 20-60 V for footpad stimulation, were accumulated for 50 consecutive stimulus trials at $0.5 \mathrm{~Hz}$.

Systemic drug administration. Intravenous (iv) injections were made into a lateral tail vein. Idazoxan $(0.1$ or $0.5 \mathrm{mg} / \mathrm{ml})$, naloxone hydrochloride $(0.5 \mathrm{mg} / \mathrm{ml})$, or picrotoxin $(3.0 \mathrm{mg} / \mathrm{ml})$ were prepared in distilled water daily.

Local microinfusion. Bicuculline methiodide (30-180 nl of a 17-330

Figure 1. Stimulation and recording sites. $A$, Photomicrograph of a coronal section ( $50 \mu \mathrm{m}$-thick; Neutral red stain) through the rostral medulla of an experimental rat brain. Prussian blue spot (shown at arrow) reveals the location of stimulation electrode tips unilaterally in PrH. $B$, Photomicrograph of a coronal section through the LC. Iontophoretic ejection of pontamine sky blue spot (at arrow) marks the location of the last cell recorded in a micropipette penetration through LC. For calibration, length of arrow in $A, 239 \mu \mathrm{m}$, and, in $B, 75 \mu \mathrm{m}$. 


\section{PrH Stim}

Figure 3. Microinfusion of bicuculline methiodide $(B I C)$ into LC blocks PrH-evoked inhibition. $A$, Peristimulus time histogram showing PrH-evoked inhibition of a LC neuron. $B$, PrHevoked inhibition shown in $A$, predrug, is blocked after infusion of $1.0 \mathrm{ng} \mathrm{BIC}$ (120 $\mathrm{nl}$ injection volume) into $\mathrm{LC}$, as shown in $B, 3$ min postdrug. $C$, $\mathrm{PrH}-$ evoked inhibition recovers 11 min after $\mathrm{BIC}$ infusion. Stimulation amplitude in $A-C, 400 \mu \mathrm{A}$. $D$, Peristimulus time histogram showing footpad stimulation (FS)-evoked excitation of the same LC neuron shown in $A-C . E$, FS-evoked excitation and postactivation inhibition in $D$ are not altered after the dose of BIC given in $B$, as shown in $E, 5$ min postdrug. Stimulation intensity in $D$ and $E, 30 \mathrm{~V}$. Stimulation is shown at arrows in all histograms.
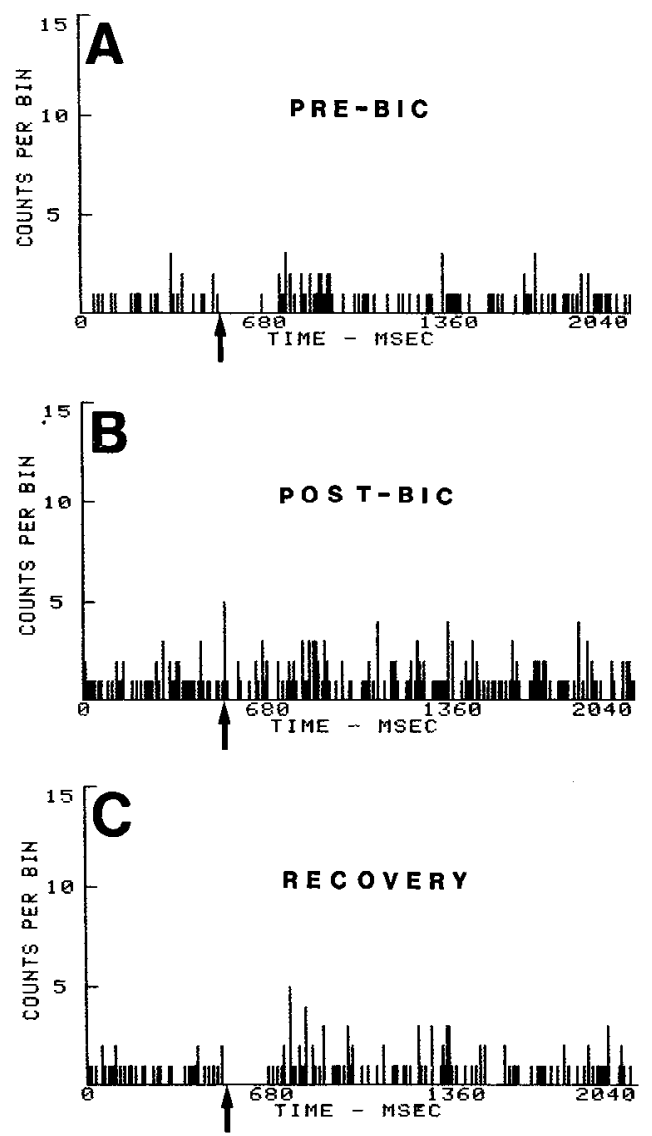

FS
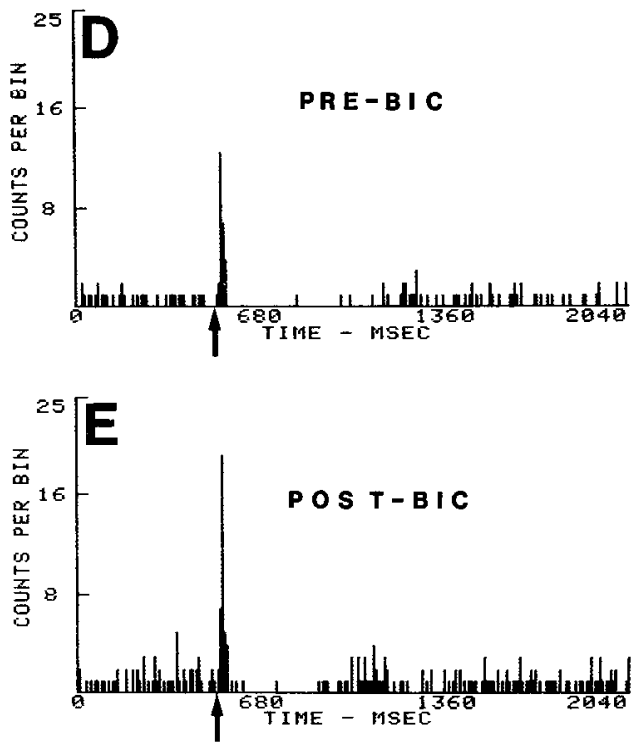

$\mu \mathrm{M}$ solution in $0.9 \%$ saline) was infused into the LC from a glass injection pipette (40-70 $\mu \mathrm{m}$ tip diameter) positioned $70-300 \mu \mathrm{m}$ from the tip of the recording pipette.

Microiontophoresis. A 7-barrel iontophoretic micropipette (10-20 $\mu \mathrm{m}$ tip diameter) was glued to an independent single-barrel recording micropipette (2-4 $\mu \mathrm{m}$-tip diameter, described above), placing the recording micropipette tip 20-35 $\mu \mathrm{m}$ below the 7-barrel array. The center and one outer barrel of the iontophoretic pipette were filled with $4 \mathrm{M} \mathrm{NaCl}$. The center $\mathrm{NaCl}$ barrel was used to neutralize continuously tip potential through an automatic current-balancing circuit, while the outer $\mathrm{NaCl}$ barrel was used for control current ejection. The other 5 barrels were filled with desired drug solutions (see below). Iontophoretic solutions were ejected with currents of 1-200 nA, and retained with currents of 1-10 nA. The following iontophoretic solutions were used: bicuculline methiodide $(0.01 \mathrm{M}, \mathrm{pH} 4), \mathrm{GABA}(0.1 \mathrm{M}, \mathrm{pH} 4)$, and strychnine hydrochloride $(0.01 \mathrm{M}, \mathrm{pH} 5)$. Continuous iontophoretic application of an antagonist was initiated $1.5 \mathrm{~min}$ before, and continued throughout, accumulation of postdrug peristimulus time histograms.

Histology. Micropipette penetrations were marked by iontophoretic ejection of dye with current pulses ( $-7 \mu \mathrm{A}, 50 \%$ duty cycle for $10 \mathrm{~min}$ ). At the end of recording sessions, $+30 \mu \mathrm{A}$ was passed through the stimulation electrode for $1 \mathrm{~min}$ to deposit iron at electrode tips. Animals were then deeply anesthetized and perfused with $10 \%$ formaldehyde in $0.1 \mathrm{M}$ phosphate buffer containing $5 \%$ potassium ferrocyanide. Brains were removed and stored in a similar solution containing $10 \%$ sucrose. Select brain regions were cut into $50-\mu \mathrm{m}$-thick frozen sections and stained with Neutral red. All stimulation and recording sites were histologically localized from such tissue sections (Fig. 1).

Data analysis. Peristimulus time histograms were used to analyze evoked responses from $\mathrm{PrH}$ or footpad stimulation. The mean and SD of counts per bin were determined for a baseline period, defined as the $500 \mathrm{msec}$ epoch preceding stimulation. The onset of excitation was defined as the first of 5 consecutive bins ( $8 \mathrm{msec}$ bin width) whose mean value exceeded mean baseline activity by $2 \mathrm{SD}$, and response offset was determined as the time at which activity had returned to be consistently within 2 SD of baseline. Response magnitude $\left(R_{\text {mag }}\right)$ for excitation was normalized for spontaneous firing (baseline) according to the following equation:

Excitation $R_{\text {mag }}=$ (counts in excitatory epoch)

- (mean counts per baseline bin $\times$ number of bins in excitatory epoch).

Inhibition was defined as an epoch of at least 15 bins in which the mean count per bin was less than $35 \%$ of that during baseline. Response magnitude for inhibition was calculated as follows:

Inhibition $R_{\text {mag }}=$ (counts in inhibitory epoch)

- (mean counts per baseline bin $\times$ number of bins in inhibitory epoch).

\section{Results}

\section{Evoked responses}

As shown for a typical cell in Figure $2 A$, single-pulse electrical stimulation $(0.5 \mathrm{~Hz})$ of $\mathrm{PrH}$ produced short-latency, phasic inhibition of LC discharge. Overall, 42 of 47 LC neurons (89\%) were inhibited from $\mathrm{PrH}$ stimulation, with a mean onset latency of $19.8 \pm 2.5 \mathrm{msec}$ and a mean duration of $172.4 \pm 10.4 \mathrm{msec}$. Two cells were synaptically activated, and 3 other cells were unaffected from such stimulation.

\section{Pharmacology of evoked responses}

Picrotoxin. The GABA antagonist picrotoxin, at doses of 3 ( $n$ $=3$ ) or $6(n=4) \mathrm{mg} / \mathrm{kg}$, iv, significantly attenuated the inhibition of LC from $\operatorname{PrH}(p<0.03$, paired $t$ test), completely blocking such inhibition in $5 / 7$ cells (Fig. 2). Picrotoxin at these doses elicited twitching of the face and flank. 


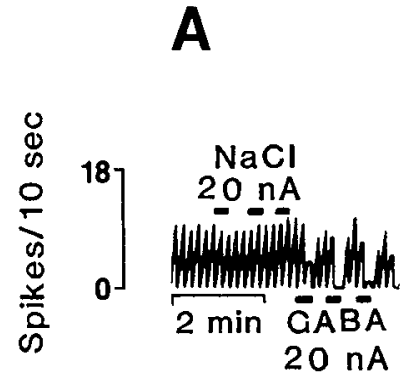

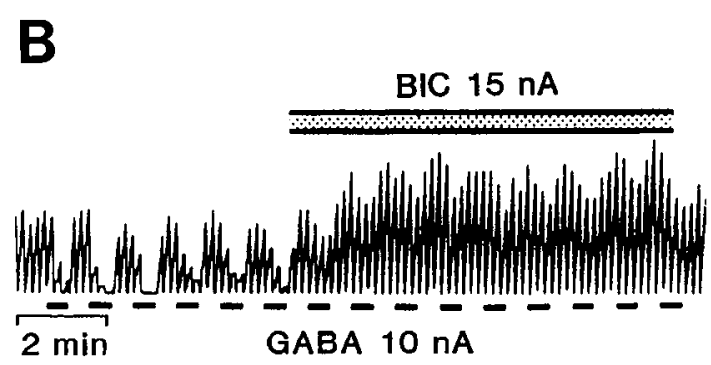

Figure 4. GABA-evoked inhibition of LC discharge is antagonized by bicuculline methiodide (BIC). $A$, Chart recording showing inhibition of the spontaneous discharge of a LC neuron elicited by iontophoretically applied pulses of GABA (indicated by thick bars below chart record). Current pulses of the same intensity through an adjacent $\mathrm{NaCl}$ barrel (at bars above chart record) have no effect on the discharge of this cell. $B$, Continuous iontophoretic application of BIC (upper stippled bar) attenuates GABA-evoked inhibition of this LC neuron (lower thick bars). Note that BIC also increases spontaneous rate.
In contrast to the blockade of inhibition from $\mathrm{PrH}$, picrotoxin had no effect on excitatory responses of LC neurons to footpad stimulation (Fig. 2), nor on the inhibitory period that followed footpad-evoked excitation ( $n=4, p>0.5$, for each).

Locally infused bicuculline methiodide. As shown in Figure 3, microinfusion of $0.5-5.0 \mathrm{ng}$ bicuculline methiodide into the LC completely blocked PrH-evoked inhibition in 10/11 cells tested ( $p<0.02$, paired $t$ test). In 3 of these neurons, bicuculline methiodide infusion also disclosed an underlying excitatory response to $\mathrm{PrH}$ stimulation not observed in predrug experiments. PrH-evoked inhibition of one LC neuron was not affected after microinfusion of bicuculline methiodide.

As illustrated in Figure 3, bicuculline methiodide microin- fusion did not significantly alter the magnitude of footpad-evoked excitation of LC neurons ( $n=5 ; p>0.3$, paired $t$ test). Similarly, postactivation inhibition following footpad-evoked excitation was not significantly affected overall after microinfusion of bicuculline methiodide ( $n=5 ; p>0.2$, paired $t$ test), although such inhibition was completely attenuated in one cell tested.

Bicuculline methiodide infusion increased the spontaneous discharge rate of LC neurons somewhat, although this tendency was not statistically significant $(n=5 ; p>0.1$, paired $t$ test).

Microiontophoresis. Iontophoretically applied GABA (5-100 $\mathrm{nA}$ ) inhibited the spontaneous discharge of 9 of $10 \mathrm{LC}$ ncurons (Fig. $4 ; p<0.001$, paired $t$ test). The magnitude of GABAevoked inhibition ranged from 29.7 to $80 \%$, with a mean value

\section{PrH Stim}

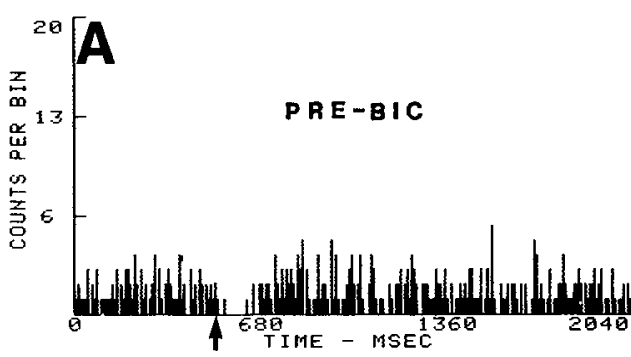

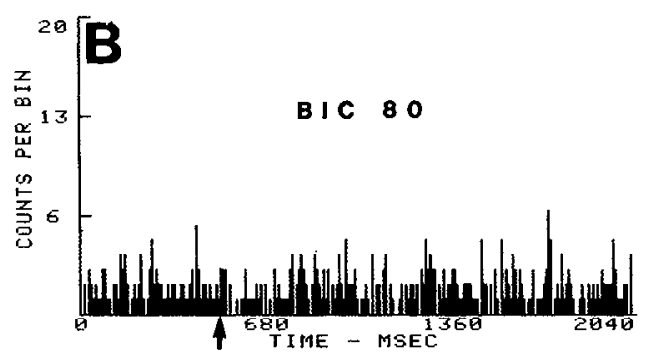

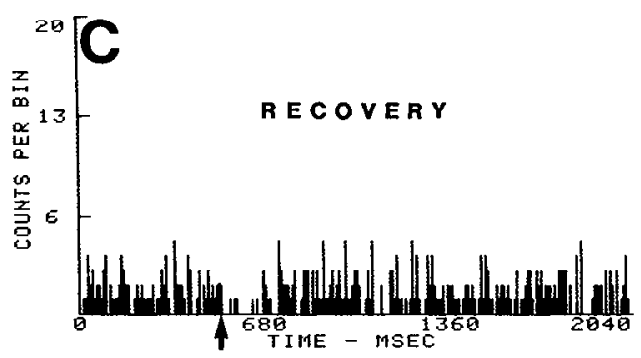

F S
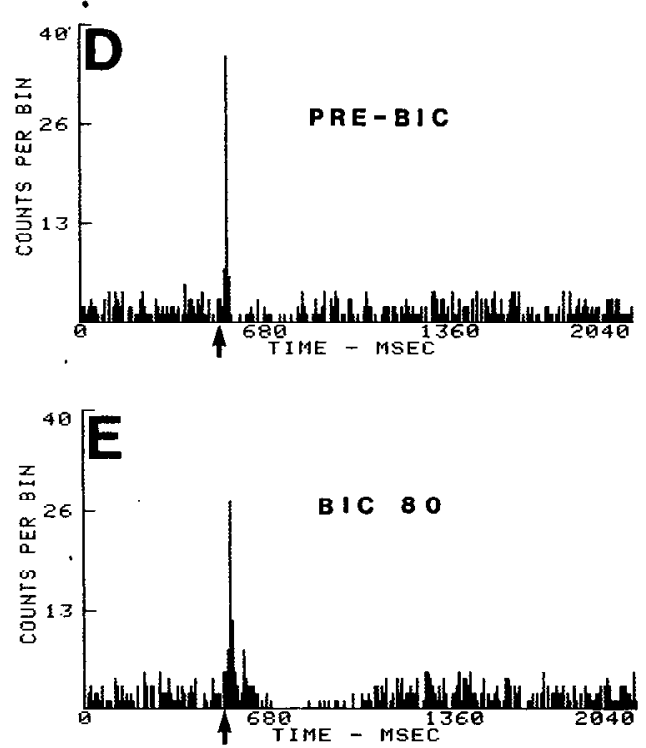

Figure 5. Iontophoretically applied bicuculline methiodide $(B I C)$ blocks inhibition of LC from PrH. A, Peristimulus time histogram showing PrHevoked inhibition of a LC neuron. $B$, PrH-evoked inhibition shown in $A$ predrug is blocked during continuous iontophoretic application of BIC ( $80 \mathrm{nA})$. $C$, PrH-evoked inhibition recovers within 5 min after terminating application of BIC. Stimulation amplitude in $A-C, 500 \mu \mathrm{A}$. $D$, Peristimulus time histogram showing footpad stimulation $(F S)$-evoked excitation of the same neuron as in $A$. $E$, FS-evoked excitation shown in $D$ predrug is not attenuated but slightly enhanced during application of BIC $(80 \mathrm{nA})$. Note that postactivation inhibition is also increased during BIC application. Stimulation amplitude in $D$ and $E, 20 \mathrm{~V}$. Stimulation is at arrow in all histograms. 


\section{PrH Stim}
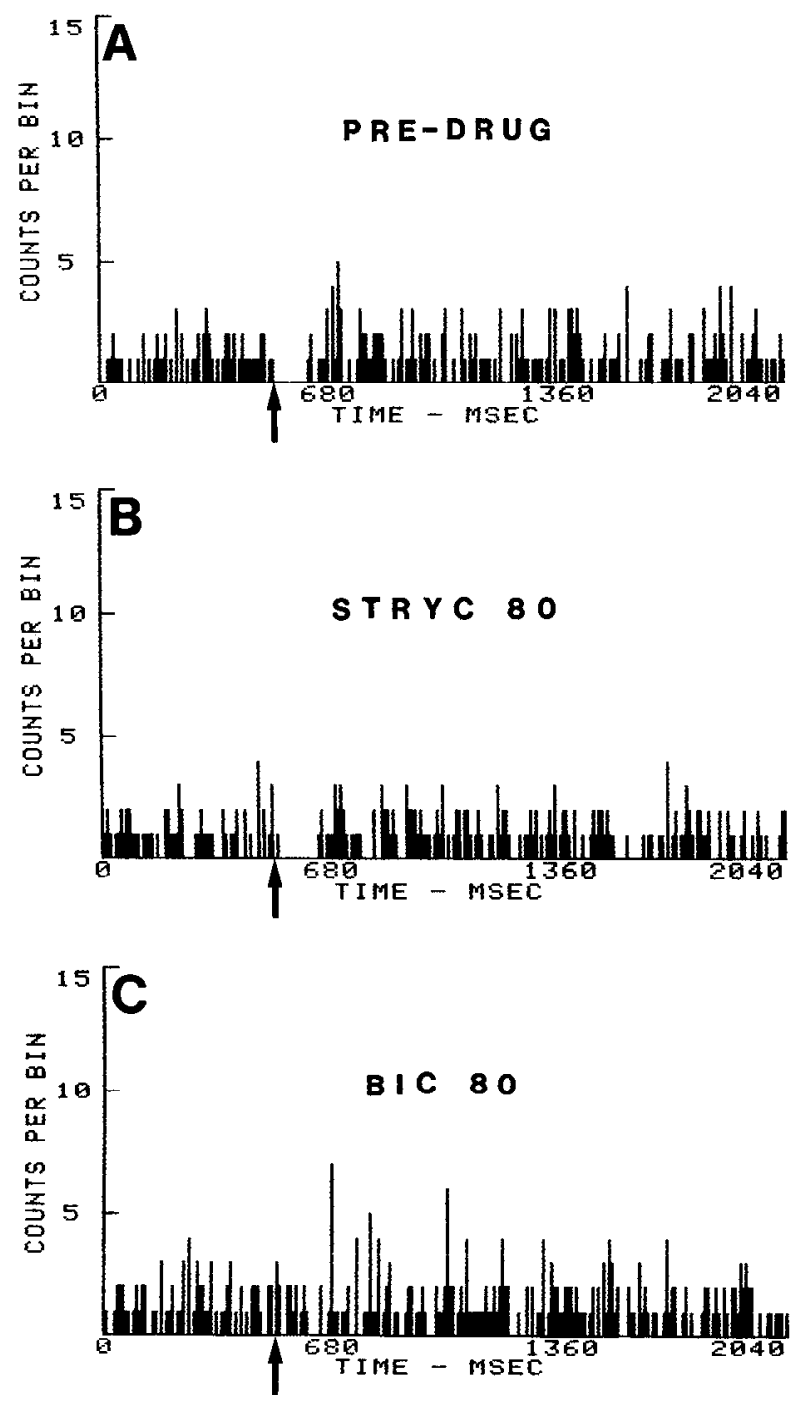

Figure 6. Iontophoretically applied strychnine (STRYC) does not attenuate PrH-evoked inhibition. A, Peristimulus time histogram showing $\mathrm{PrH}$-evoked inhibition of a $\mathrm{LC}$ neuron (stimulation is at arrow). $B, \mathrm{PrH}-$ evoked inhibition of the same neuron shown in $A$, predrug, is not attenuated during continuous application of strychnine $(80 \mathrm{nA})$. $C$, Iontophoretic application of bicuculline methiodide (BIC, $80 \mathrm{nA}$ ) onto the same cell completely blocks $\mathrm{PrH}$-evoked inhibition. Stimulation intensity in $A-C, 400 \mu \mathrm{A}$.

of 58.6\%. Current ejection through an adjacent $\mathrm{NaCl}$ electrode did not affect LC discharge. Iontophoretically applied bicuculline methiodide significantly decreased the magnitude of GABAevoked inhibition of LC discharge (mean decrease, $65.3 \% ; n=$ $5, p<0.02$, Mann-Whitney test), although bicuculline methiodide did not completely reverse this inhibition (Fig. 4). Continuous iontophoretic application of bicuculline methiodide (20$100 \mathrm{nA}$ ) increased the mean spontaneous discharge rate of LC neurons $(n=10)$ from $2.1 \pm 0.3$ to $3.1 \pm 0.4 \mathrm{~Hz}(p<0.004$, paired $t$ test). The increase in spontaneous discharge evoked by bicuculline methiodide was of slow onset, typically developing after 1.5-3 min. Application of bicuculline methiodide with high currents $(>100 \mathrm{nA})$ or for prolonged periods often increased the spontaneous discharge rate of $\mathrm{LC}$ neurons to $6-10 \mathrm{~Hz}$.
The effect of iontophoretically applied bicuculline methiodide on PrH-evoked inhibition of LC was examined with 22 neurons. Bicuculline methiodide (20-100 nA) completely blocked such inhibition in 19/22 cells tested (Figs. 5, 6) and caused a significant overall attenuation of this response $(p<0.01$, paired $t$ test). Full or partial recovery of PrH-evoked inhibition was observed 5-12 min after termination of the ejection current. Inhibition of LC discharge from PrH was not altcred by cjection of similar currents through an adjacent barrel containing $\mathrm{NaCl}$ $(n=6 ; p>0.1$, paired $t$ test).

In 5 of these neurons, iontophoretic application of bicuculline methiodide converted the inhibitory response to $\mathrm{PrH}$ stimulation into an excitation. Such excitation rapidly decayed after termination of bicuculline methiodide, with evoked inhibition returning after $2-10 \mathrm{~min}$.

As shown in Figure 5, footpad-evoked excitation of LC neurons was not significantly affected by iontophoretically applied bicuculline methiodide $(n=9 ; p>0.5$, paired $t$ test). In addition, bicuculline methiodide had no overall effect on postactivation inhibition following such excitation $(n=7, p>0.1$, paired $t$ test), although such inhibition was blocked in one cell.

In contrast to bicuculline methiodide, iontophoretic application of the glycine antagonist strychnine hydrochloride (80$100 \mathrm{nA}$ ) did not affect the magnitude of PrH-evoked inhibition of LC discharge ( $n=6 ; p>0.1$, paired $t$ test; Fig. 6$)$.

Idazoxan. Idazoxan at doses of $0.1 \mathrm{mg} / \mathrm{kg}(n=1)$ or $0.5 \mathrm{mg} /$ $\mathrm{kg}(n=5)$, iv, did not significantly attenuate the magnitude of PrH-evoked inhibition (Fig. 7; $p>0.1$, paired $t$ test), nor did it block such inhibition in any individual neuron. As expected, idazoxan significantly increased the mean spontaneous discharge rate of these neurons from $1.6 \perp 0.4$ to $2.5 \pm 0.4 \mathrm{~Hz}$ ( $n$ $=6, p<0.005$, paired $t$ test).

Naloxone. As illustrated for a typical cell in Figure 8, naloxone $(0.5$ or $1.0 \mathrm{mg} / \mathrm{kg}$, iv) did not attenuate $\mathrm{PrH}$-evoked inhibition of LC discharge ( $n=5 ; p>0.10$, paired $t$ test) and did not alter the spontaneous discharge rate of $\mathrm{LC}$ neurons $(n=4 ; p>0.4$, paired $t$ test).

\section{Discussion}

The present study has characterized the regulatory influence of the PrH on the activity of LC neurons. Our results indicate that $\mathrm{PrH}$, anatomically identified as 1 of 2 major afferent inputs to LC (Aston-Jones et al., 1986), exerts a nearly uniformly inhibitory influence on the discharge of LC neurons. In addition, our pharmacologic analysis indicates that $\mathrm{PrH}$-evoked inhibition of LC is mediated by GABA, acting primarily at the $\mathrm{GABA}_{\mathrm{A}}$ receptor subtype.

Several findings indicate that the inhibition of IC neurons from $\mathrm{PrH}$ stimulation is a direct response to input from cells in the $\operatorname{PrH}$ area. (1) The latency for synaptic inhibition of LC neurons from $\mathrm{PrH}$ (mean onset latency $=19.8 \mathrm{msec}$ ) is similar to the latencies for $\mathrm{PrH}$ neurons antidromically activated from LC (range of latencies $=10-23 \mathrm{msec}$, mean latency $=16 \mathrm{msec}$; Ennis and Aston-Jones, 1989), indicating that the responses observed here result from activation of a slowly conducting fiber pathway from PrH cells. (2) Stimulation of the nucleus tractus solitarius in the dorsal medulla caudal to $\mathrm{PrH}$ has no consistent effect on the discharge of LC neurons (Ennis and Aston-Jones, 1989). Activation of the other major afferent input to LC, nucleus paragigantocellularis in the ventrolateral medulla, yields predominant activation of LC neurons (Ennis and Aston-Jones, 
1988). Structures adjacent to $\mathrm{PrH}$ (i.e., medial vestibular nucleus) do not project to LC (Aston-Jones et al., 1986). (3) No LC neurons were antidromically activated, and only 2 cells were synaptically activated from $\mathrm{PrH}$ stimulation, indicating that $\mathrm{PrH}$ evoked inhibition is not due to collateral-mediated postactivation inhibition reported for LC neurons (Aghajanian et al., 1977; Cedarbaum and Aghajanian, 1978a; Ennis and AstonJones, 1986b). Furthermore, the failure of the $\alpha_{2}$-receptor antagonist idazoxan to block PrH-evoked inhibition (see below) provides additional evidence that this inhibition is not mediated by noradrenergic collateral interactions in LC or by epinephrine inputs from the ventrolateral medulla (Pieribone et al., 1988).

The neurochemical identity of projections from PrH to LC have not been fully characterized with double-labeling techniques. However, recent experiments (Pieribone et al., 1988) reveal that although $\mathrm{PrH}$ neurons retrogradely labeled from LC are located in the area of the C3 adrenergic cell group, there appear to be only minor adrenergic projections from $\mathrm{PrH}$ to LC. The present finding that high intravenous doses of the $\alpha_{2}$ receptor antagonist idazoxan did not alter PrH-evoked inhibition is consistent with these anatomic results indicating no prominent adrenergic input to LC from $\mathrm{PrH}$.

Immunohistochemical studies by others demonstrate the presence of enkephalin-containing cells in PrH (Khachaturian et al., 1983) and enkephalinergic fibers in LC (Pickel et al., 1979). However, the lack of effect of naloxone in the present experiments, at a dose well above that previously shown to reverse opiate-induced inhibition of LC (Bardo et al., 1983), indicates that PrH-evoked inhibition of LC neurons is probably not mediated by enkephalin.

Some $\mathrm{PrH}$ neurons also stain for glutamic acid decarboxylase (Mugnaini and Oertel, 1985), a synthetic enzyme for GABA, and for GABA itself (Pieribone et al., unpublished observations). In addition, immunohistochemical studies reveal a rich plexus of glutamic acid decarboxylase-positive fibers and terminals in LC (Berod et al., 1984; Mugnaini and Oertel, 1985; Ijima and Ohtomo, 1988; Shipley et al., 1988), and GABA receptors have also been demonstrated in the LC (Wamslcy and Palacios, 1984). The possibility that GABA may mediate PrHevoked inhibition of $\mathrm{LC}$ is consistent with in vivo and in vitro pharmacologic findings here and elsewhere that GABA directly applied inhibits spontaneous discharge of LC neurons (Cedarbaum and Aghajanian, 1976, 1977; Guyenet and Aghajanian, 1979; Osmanovic and Shefner 1987, 1988). However, recent studies also have disclosed GAD-positive neurons in the vicinity of LC (Ijima and Ohtomo, 1988; Shipley et al., 1988); these results raise the possibility that some $\mathrm{PrH}$ afferents may act through such local GABAergic neurons.

In the present experiments, iontophoretically applied GABA inhibited the spontaneous discharge rate of LC neurons by as much as $80 \%$. Bicuculline methiodide, a selective $\mathrm{GABA}_{\mathrm{A}}$ receptor antagonist (Lloyd and Morselli, 1987), attenuated GABAevoked inhibition by 58-70\%. GABA-evoked inhibition remaining in the presence of bicuculline may be mediated by the action of GABA on bicuculline-insensitive $\mathrm{GABA}_{\mathrm{B}}$ receptors, as Osmanovic and Shefner (1988) have reported that GABA simultaneously inhibits $L C$ neurons via activation of $G_{A B A}$ and $\mathrm{GA} \mathrm{BA}_{\mathrm{B}}$ receptor subtypes. Iontophoretically applied bicuculline methiodide increased the spontaneous discharge rate of some LC neurons; in some cases, spontaneous rate was increased above the normal discharge rates of LC neurons in anesthetized rats $(0.5-5.0 \mathrm{~Hz})$, indicating that this effect may

\section{PrH Stim.}
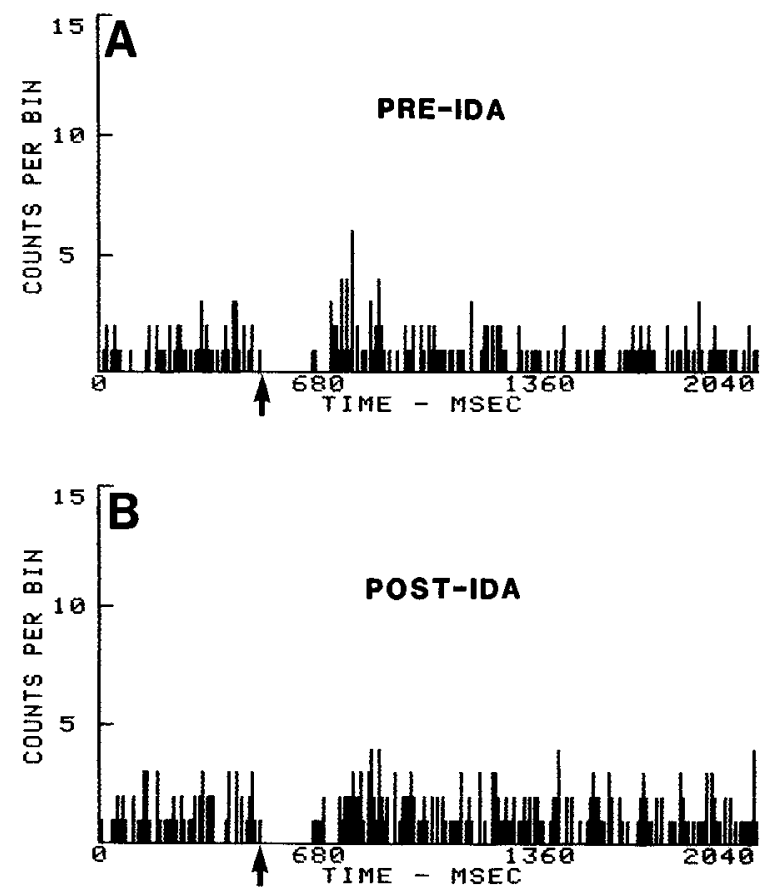

Figure 7. Lack of effect of the $\alpha_{2}$-receptor antagonist idazoxan (IDA) on PrH-evoked inhibition of LC discharge. $A$, Peristimulus time histogram showing inhibition of a $\mathrm{LC}$ neuron elicited from $\mathrm{PrH}$ stimulation (at arrow). $B$, PrH-evoked inhibition shown in $A$, predrug, is not altered $1.5 \mathrm{~min}$ after $0.5 \mathrm{mg} / \mathrm{kg}$ idazoxan (iv). Stimulation intensity in $A$ and $B, 750 \mu \mathrm{A}$

not be due simply to antagonism of GABA leakage from the iontophoretic pipette, but may reflect tonically active GABAergic input to LC.

The ability of intravenous picrotoxin to attenuate or completely block PrH-evoked inhibition of LC neurons indicates that this inhibition is mediated by GABAergic projections from $\operatorname{PrH}$ to LC. This finding is tempered by observations that the effects of picrotoxin are not of sufficient specificity to delineate GABA-mediated responses conclusively. However, several other results of the present studies indicate that PrH-evoked inhibition is mediated by GABA. (1) Local infusion or microiontophoretic application of the specific $\mathrm{GABA}_{\mathrm{A}}$ receptor antagonist bicuculline methiodide blocked PrH-evoked inhibition in the majority of cells tested with this agent, (2) iontophoretic application of the glycine antagonist strychnine did not antagonize $\mathrm{PrH}$-evoked inhibition of LC neurons, and (3) picrotoxin and bicuculline methiodide did not significantly alter excitation or postactivation inhibition of LC cells following footpad stimulation, indicating that these agents did not have nonspecific effects on other synaptically mediated responses of LC neurons.

It should be noted that in some LC neurons bicuculline methiodide revealed an underlying excitatory response to $\mathrm{PrH}$ stimulation that was not observed in these cells prior to administration of this agent. The number of cells excited from $\mathrm{PrH}$ after bicuculline methiodide administration $(8 / 33)$ was greater than the number of cells excited in control studies $(2 / 47)$. These findings indicate that there may be a modest excitatory component in the pathway from $\mathrm{PrH}$ to $\mathrm{LC}$ in addition to the more prominent GABAergic projections. Thus, in control stimulation 

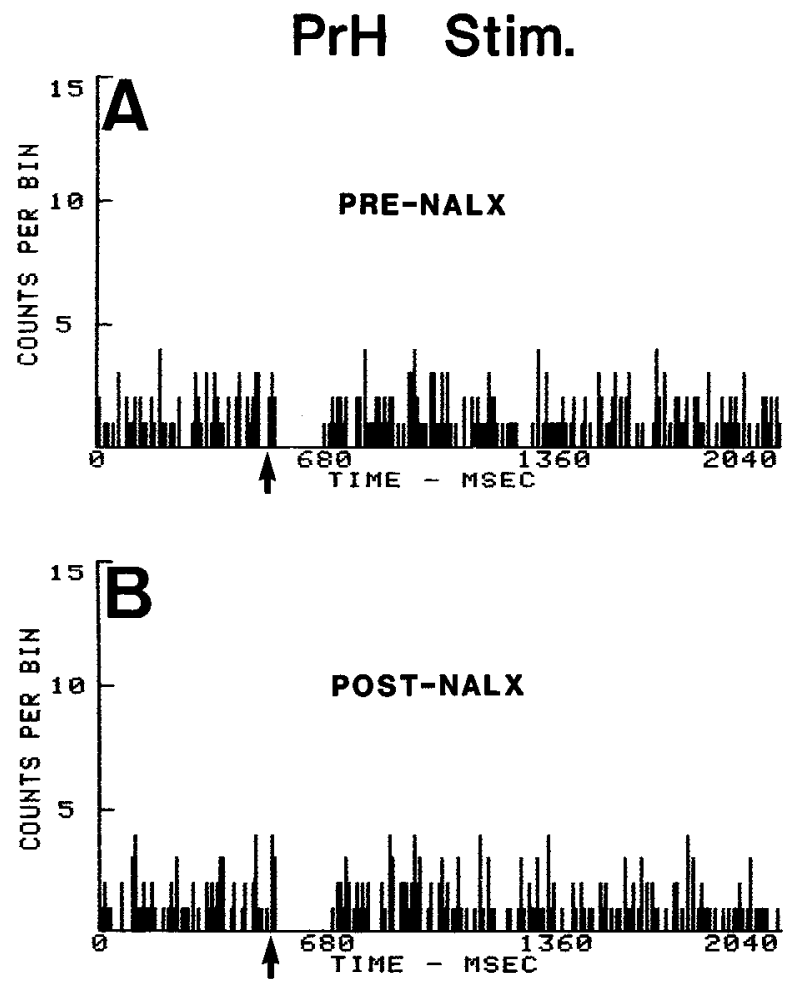

Figure 8. Naloxone (NALX) does not affect PrH-evoked inhibition of LC discharge. $A$, Peristimulus time histogram showing $\mathrm{PrH}$-evoked inhibition of a LC neuron (stimulation is at arrow). $B$, PrH-evoked inhibition of the same neuron is not altered after $1.0 \mathrm{mg} / \mathrm{kg}$ (iv) of naloxone. Stimulation intensity in $A$ and $B, 615 \mu \mathrm{A}$.

experiments, activation of inhibitory inputs from $\mathrm{PrH}$ may predominate and mask the influence of less potent excitatory projections. Such an effect of GABA is consistent with the membrane hyperpolarization and "shunting" actions of this neurotransmitter (Alger, 1985); both of these effects would tend to decrease the response to a coactivated excitatory input to the same cell. Additional experiments are necessary to confirm possible excitatory projections from $\mathrm{PrH}$ to $\mathrm{LC}$.

Our conclusion that PrH-evoked inhibition of LC neurons is mediated by GABA, operating primarily at a $\mathrm{GABA}_{\mathrm{A}}$ receptor, is in agreement with recent observations in vitro by Cherubini et al. (1988). Electrical field stimulation of LC slices elicit both excitatory and inhibitory postsynaptic potentials measured intracellularly in LC neurons. Such postsynaptic potentials are not observed in a low-calcium medium (Egan et al., 1983) and are presumably mediated by neurotransmitter released from terminals of afferent fibers contained in the slice. Cherubini et al. have demonstrated that such field stimulation-evoked postsynaptic potentials consist of 2 primary components distinguished on the basis of pharmacologic sensitivity and ionic dependence: (1) a bicuculline-insensitive postsynaptic potential, antagonized by the excitatory amino acid antagonist kynurenic acid, and (2) a kynurenic acid-insensitive, chloride-dependent postsynaptic potential antagonized by bicuculline. Cherubini et al. conclude that the postsynaptic potential antagonized by bicuculline results from stimulation-evoked release of GABA. In light of the present in vivo findings, it seems probable that this bicucullinesensitive postsynaptic potential is mediated, at least in part, by GABA released from $\mathrm{PrH}$ terminals in the $\mathrm{LC}$ slice. We have previously reported that activation of paragigantocellularis excites LC neurons, an effect that is blocked by the excitatory amino acid antagonists kynurenic acid or gamma-D-glutamylglycine (Ennis and Aston-Jones, 1988). The postsynaptic potential observed by Cherubini et al. that was antagonized by kynurenic acid, but not by bicuculline, may be mediated by an excitatory amino acid released from terminals of paragigantocellularis fibers contained in the LC slice.

The function of this major inhibitory input to LC is at present unclear. However, previous experiments recording LC activity in unanesthetized behaving rats (Aston-Jones and Bloom, 1981) found that these neurons were largely silent during paradoxical sleep. Examination of field potential activity in LC in this same study indicated that the markedly reduced spontaneous and sensory-evoked discharge during paradoxical sleep was probably the result of tonic inhibition impinging on $\mathrm{LC}$ from an extrinsic afferent. It was further proposed that such a tonic inhibitory afferent may be responsible for the decreased activity and sensory responsiveness found for these cells during other nonvigilant behaviors such as slow-wave sleep, grooming, and consumption. The inhibition reported here from $\mathrm{PrH}$ could reveal the pathway responsible for such behavioral state-dependent inhibition of LC. The input from PrH is not the only possible source of such inhibition, however. Recent results (Pieribone et al., 1988) demonstrate a prominent adrenergic input to LC from the nucleus paragigantocellularis in the rostral ventrolateral medulla, and previous studies have shown epinephrine to be inhibitory on LC discharge (Cedarbaum and Aghajanian, 1976, 1977). Thus, this adrencrgic pathway from the paragigantocellularis provides another source of inhibitory control over LC in addition to the presently described GABAergic projection from $\mathrm{PrH}$. Experiments are underway to clarify the function of these inhibitory afferents to LC and to determine if these inputs mediate state-dependent inhibition of LC.

In conclusion, our results identify a strong inhibitory synaptic input to LC, emanating from a major afferent to this nucleus, $\mathrm{PrH}$. This inhibition appears to be mediated by GABA, acting at the $\mathrm{GABA}_{\mathrm{A}}$ receptor subtype on $\mathrm{LC}$ neurons.

\section{References}

Aghajanian, G. K., J. M. Cedarbaum, and R. Y. Wang (1977) Evidence for norepinephrine-mediated collateral inhibition of locus coeruleus neurons. Brain Res. 136: 570-577.

Alger, B. E. (1985) GABA and glycine: postsynaptic actions. In $\mathrm{Neu}-$ rotransmitter Actions in the Vertebrate Nervous System, M. A. Rogawski and J. L. Barker, eds., pp. 33-69, Plenum, New York.

Altman, J., and S. A. Bayer (1980) Development of the brain stem in the rat. III. Thymidine-radiographic study of the time of origin of neurons of the vestibular and auditory nuclei of the upper medulla. J. Comp. Neurol. 194: 877-904.

Aston-Jones, G., and F. E. Bloom (1981) Activity of norepinephrinecontaining locus coeruleus neurons in behaving rats anticipates fluctuations in the sleep-waking cycle. J. Neurosci. 1: 876-886.

Aston-Jones, G., S. L. Foote, and F. E. Bloom (1982) Low doses of ethanol disrupt sensory responses of brain noradrenergic neurons. Nature 296: 857-860.

Aston-Jones, G., M. Ennis, V. A. Pieribone, W. T. Nickell, and M. T. Shipley (1986) The brain nucleus locus coeruleus: Restricted afferent control of a broad efferent network. Science 234: 734-737.

Bardo, M. T., R. K. Bhatnagar, and G. F. Gebhart (1983) Chronic naltrexone increases opiate binding in brain and produces supersensitivity to morphine in the locus coeruleus of the rat. Brain Res. 289: 223-234.

Berod, A., M. Chat, L. Paut, and M. Tappaz (1984) Catecholaminergic and GABAergic analomical relationship in the ral substantia nigra, locus coeruleus, and hypothalamic median eminence: Immunocyto- 
chemical visualization of biosynthetic enzymes on serial semithin plastic-embedded sections. J. Histochem. Cytochem. 32: 1331-1338.

Cedarbaum, J. M., and G. K. Aghajanian (1976) Noradrenergic neurons of the locus coeruleus: Inhibition by epinephrine and activation of the $\alpha$-antagonist piperoxane. Brain Res. 112: 413-419.

Cedarbaum, J. M., and G. K. Aghajanian (1977) Catecholamine receptors on locus coeruleus neurons: Pharmacological characterization. Eur. J. Pharmacol. 44: 375-385.

Cedarbaum, J. M., and G. K. Aghajanian (1978a) Activation of the locus coeruleus by peripheral stimuli: Modulation by a collateral inhibitory mechanism. Life Sci. 23: 1383-1392.

Cedarbaum, J. M., and G. K. Aghajanian (1978b) Afferent projections to the rat locus coeruleus as determined by a retrograde tracing technique. J. Comp. Neurol. 178: 1-16.

Cherubini, E., R. A. North, and J. T. Williams (1988) Synaptic potentials in rat locus coeruleus neurones. J. Physiol. (Lond.) 406: 431-442.

Egan, T. M., G. Henderson, R. A., North, and J. T. Williams (1983) Noradrenaline-mediated synaptic inhibition in rat locus coeruleus neurones. J. Physiol. (Lond.) 345: 477-488.

Ennis, M., and G. Aston-Jones (1986a) A potent excitatory input to the locus coeruleus from the ventrolateral medulla. Neurosci. Lett. 71:299-305.

Ennis, M., and G. Aston-Jones (1986b) Evidence for self- and neighbor-mediated postactivation inhibition of locus coeruleus neurons. Brain Res. 374: 299-305.

Ennis, M., and G. Aston-Jones (1988) Activation of locus coeruleus from nucleus paragigantocellularis: A new excitatory amino acid pathway in brain. J. Neurosci. 8: 3644-3657.

Ennis, M., and G. Aston-Jones (1989) Potent inhibitory input to locus coeruleus from the nucleus prepositus hypoglossi. Brain Res. Bull. 22: 793-803.

Guyenet, P. G., and G. K. Aghajanian (1979) Ach, substance P, and met-enkephalin in the locus coeruleus: Pharmacological evidence for independent sites of action. Eur. J. Pharmacol. 53: 319-328.

Hökfelt, T., K. Fuxe, M. Goldstein, and O. Johansson (1974) Immunohistochemical evidence for the existence of adrenaline neurons in the rat brain. Brain Res. 66: 235-251.

Hökfelt, T., R. Martensson, A. Bjorklund, S. Lleinau, and M. Goldstein (1984) Distributional maps of tyrosinc-hydroxylasc-immunorcactive neurons in the rat brain. In Handbook of Chemical Neuroanatomy, Vol. 2: Classical Transmitters in the CNS, A. Bjorklund and T. Hökfelt, eds., pp. 277-379, Elsevier, Amsterdam.
Howe, P. R. C., M. Costa, J. B. Furness, and J. P. Chalmers (1980) Simultaneous demonstration of phenylethanolamine N-methyltransferase immunofluorescent and catecholamine fluorescent nerve cell bodies in the rat medulla oblongata. Neuroscience 5: 2229-2238.

Ijima, K., and K. Ohtomo (1988) Immunocytochemical study using a GABA antiserum for the demonstration of inhibitory neurons in the rat locus coeruleus. Am. J. Anat. 181: 43-52.

Khachaturian, H., M. E. Lewis, and S. J. Watson (1983) Enkephalin systems in diencephalon and brainstem of the rat. J. Comp. Neurol. 220: $310-320$.

Lloyd, K. G., and P. L. Morselli (1987) Psychopharmacology of GABAcrgic drugs. In Psychopharmacology: The Third Generation of Progress, H. Y. Meltzer, ed., pp. 183-195, Raven, New York.

Mugnaini, E., and W. H. Oertel (1985) An atlas of the distribution of GABAergic neurons and terminals in the rat CNS as revealed by GAD immunohistochemistry. In Handbook of Chemical Neuroanatomy, Vol. 4, GABA and Neuropeptides in the CNS, A. Bjorklund and T. Hökfelt, eds., pp. 436-608, Elsevier, Amsterdam.

Osmanovic, S. S., and S. A. Shefner (1987) Properties of $\mathrm{GABA}_{A^{-}}$ activated conductance in rat locus coeruleus neurons in vitro. Soc. Neurosci. Abstr. 13: 151.

Osmanovic, S. S., and S. A. Shefner (1988) Baclofen increases the potassium conductance of rat locus coeruleus neurons recorded in brain slices. Brain Res. 438: 124-136.

Palkovits, M., and D. M. Jacobowitz (1974) Topographic atlas of catccholaminc and acctylcholinesterase-containing neurons in the rat brain. II. Hindbrain (mesencephalon, rhombencephalon). J. Comp. Neurol. 157: 29-42.

Pickel, V. M., T. H. Joh, D. J. Reis, S. E. Leeman, and R. J. Miller (1979) Electron microscopic localization of substance $P$ and enkephalin in axon terminals related to dendrites of catecholaminergic neurons. Brain Res. 160: 387-400.

Pieribone, V. A., G. Aston-Jones, and M. Bohn (1988) Adrenergic and non-adrenergic neurons in the $\mathrm{Cl}$ and $\mathrm{C} 3$ area project to the locus coeruleus: A fluorescent double labeling study. Neurosci. Lett. 85: 297-303.

Shipley, M. T., V. A. Pieribone, G. Aston-Jones, and M. Ennis (1988) GABA-ergic innervation of the rat locus coeruleus. Soc. Neurosci. Abstr. 14: 406.

Wamslcy, J. K., and J. M. Palacios (1984) Amino acid and benzodiazepine receptors. In Handbook of Chemical Neuroanatomy, Vol. 3, Classical Transmitters and Receptors in the CNS, A. Bjorklund, T. Hökfelt, and M. J. Kuhar, eds., pp. 352-385, Elsevier, Amsterdam. 